\title{
International Student's Challenge and Adjustment to College
}

\author{
Hsiao-ping Wu, ${ }^{1}$ Esther Garza, ${ }^{1}$ and Norma Guzman ${ }^{2}$ \\ ${ }^{1}$ Texas A\&M University-San Antonio, San Antonio, TX 78224, USA \\ ${ }^{2}$ Texas A\&M University-Kingsville, Kingsville, TX 78363, USA \\ Correspondence should be addressed to Hsiao-ping Wu; hwu@tamusa.tamus.edu
}

Received 14 September 2014; Revised 30 December 2014; Accepted 15 January 2015

Academic Editor: David Neumann

Copyright (C) 2015 Hsiao-ping Wu et al. This is an open access article distributed under the Creative Commons Attribution License, which permits unrestricted use, distribution, and reproduction in any medium, provided the original work is properly cited.

\begin{abstract}
International students' enrollment in higher education in the US has expanded considerably in the last decades. In this study, international students' experiences were examined in academic and sociocultural settings. Through qualitative interviews, the findings revealed that international students deal with academic challenges, social isolation, and cultural adjustment. Specifically, academic challenges included communication with professors, classmates, and staff. Consequently, they have to deal with social isolation when engaging in different group activities. Culturally, they need to confront the different ways of thinking and doing in the US. In order to overcome these challenges, students have adopted resources that mainly are derived from the university to overcome these challenges. Thus, as demonstrated in this study, having a better understanding of these students' academic challenges, university faculty and staff can recognize students' needs and effectively offer supportive campus resources and services. The university needs to be prepared to meet students not only academically but also socially and culturally. This study also suggests that some preparations need to be made by the university that will embrace international students upon their arrival.
\end{abstract}

\section{Introduction}

Given the recent demand for internationalization and globalization of our world, a cross-border student mobility around the world has ensued [1]; the inflow of international students in the United States (US) has increased significantly. According to the Open Doors Report of 2011 [2], there was a five percent increase in the world total of international students coming to the US or 723,277 . Table 1 demonstrates the top 10 places of origin of international students from 2009 to 2011. As exemplified in the table, most international students are from Asian backgrounds such as China, India, South Korean, and Taiwan. In addition, recent rent data from Open Doors Reports in 2012 [3] has continued showing an increasing enrollment that is up to 764,495 in the US.

\section{The Value of Embracing International Students}

International students study at thousands of colleges and universities in all 50 US states [4]. They contribute to the diversity and internationalization of their classrooms, campuses, and communities. For example, these students add different perspectives in the classroom and enhance the mutual understanding and appreciation of the differences found around the world. Therefore, it is critical to embrace international students on US campuses because of their contributions that have positively influenced the student population on so many different levels. These levels that are influenced include academic prestige, cultural exchange, and financial revenue.

To begin with, among different students, international students are extremely crucial to US higher education for both academic prestige and financial benefits [1]. Celleja [5] found that American students can have advantages if they attend a school enrolling substantial numbers of international students. For example, international students enhance the academic excellence of the colleges and universities they attend because they are academically well prepared academically. Many international students are high ranked in their home countries; however, they have to also meet requirements in academic and language aspects. Namely, these students bring new divergent ways of thinking and catalyze academic competition. 
TABLE 1: Top 10 places of origin of international students, 2009/102010/11.

\begin{tabular}{lccccc}
\hline Rank Place of origin & $2009 / 10$ & $2010 / 11$ & $\begin{array}{c}2010 / 11 \% \\
\text { of total }\end{array}$ & \% change \\
\hline & World total & 690,923 & 723,277 & 100.0 & 4.7 \\
1 & China & 127,822 & 157,558 & 21.8 & 23.3 \\
2 & India & 104,897 & 103,895 & 14.4 & -1.0 \\
3 & South Korea & 72,153 & 73,351 & 10.1 & 1.7 \\
4 & Canada & 28,145 & 27,546 & 3.8 & -2.1 \\
5 & Taiwan & 26,685 & 24,818 & 3.4 & -7.0 \\
6 & Saudi Arabia & 15,810 & 22,704 & 3.1 & 43.6 \\
7 & Japan & 24,842 & 21,290 & 2.9 & -14.3 \\
8 & Vietnam & 13,112 & 14,888 & 2.1 & 13.5 \\
9 & Mexico & 13,256 & 13,713 & 1.9 & 2.0 \\
10 & Turkey & 12,397 & 12,184 & 1.7 & -1.7 \\
\hline
\end{tabular}

Source: Open Doors Report, 2011 [2].

Secondly, international students constitute an increasingly relevant and important source of diversity on college campuses. They enrich the cultural diversity of campuses with their home culture and ethnic experiences. In addition, international students help the faculty and students to develop their cultural sensitivities and skills in working with people from different backgrounds. International students can provide opportunities for American faculty, students, and US society to experience different languages, cultures, and traditions. Hammer et al. [6] discovered that "as one's experience of cultural difference become more complex and sophisticated, one's potential competence in intercultural relationship increases" (page 423). Moreover, as an individual is exposed to diverse cultures, he or she has multiple opportunities to compare and construct a more diverse worldview.

Thirdly, international students also represent a large economic and international relations investment for American universities [2] through their expenditures on tutoring and living expenses. Most international student funding comes from personal and family sources or other sources outside of the United States. These students help universities generate higher revenue in terms of tuition and other fees. Therefore, from an economic standpoint, international students contribute significantly financially to American universities and if their needs are met, they can be the best bridge for future international students that will continue this contributory process.

However, many international students face challenges as they pursue higher education outside of their home countries $[7,8]$. They face obstacles, such as different food, unfamiliar living circumstances, financial problems, balancing work, studying schedules, learning styles, or any difficulties related to language, culture, and personal barriers. A series of transitional difficulties can be from daily life to cultural adaption $[9,10]$. If American colleges are going to embrace international students on their campuses, these issues should be addressed and accommodated. The current study is, therefore, situated based on the following: Texas ranks high in hosting international students in higher education for the past few years. The Institute of International Education (2012) has also shown that Texas is the one of top three choices when international students study abroad. For these reasons, this qualitative study will explore the following research questions: (1) what are international students' academic, social, cultural struggles in Texas? (2) What support and resources are needed for overcoming these struggles?

\section{Theoretical Framework}

International students cannot escape the cultural shock and change they experience during their studies in the US. Hence, these changes can be attributed to the acculturation process. These changes occur across physical, biological, cultural, social relationship, and psychological (behavior and mental health status) domains [11]. Berry [12] has proposed a transactional model of stress and coping in which he surmises that psychological health and adjustment are influenced by an individual's acculturation experience, the appraisal of acculturative stressors, and the coping skills used. The acculturation process can be positive, improving one's life chances and mental health in the majority/dominant culture, or it can be negative. The negative part of the acculturation process can occur due to the inherently challenging nature of change and adaptation to new cultural and social expectations [11, 13]. Similarly, the success of a sojourn or a temporary stay in a new culture is often conceived, in the psychological literature, in terms of "adjustment." It can occur in two aspects, namely, psychological and sociocultural adjustment [14]. Psychological adjustments is defined as relating to the mental health and overall well-being of migrant [15], whereas sociocultural adjustment is defined as relating to the behavioral and cognitive factors that are associated with effective performance during cross-cultural transition [16].

\section{Literature Review}

For most international students, entering US universities and colleges can be an overwhelming life and cultural transition. Many studies [17-21] explored the challenges and hurdles experienced by international students attending institutions of higher education in the US. These difficulties include, but are not limited to, language difficulties, difficulties adjusting to the academic culture, misunderstanding, and complications in communication with faculty and peers; stress, anxiety, feeling of isolation, social experiences, culture shock, financial hardships, lack of appropriate accommodation, isolation and loneliness, and any adaption in their daily life.

In many aspects, international students perceive the isolation and loneliness when they are studying in the US. In a recent study conducted among 900 international students in Australia, Russell et al. [22] found that $41 \%$ of international students experience substantial levels of stress. This stress could be from homesickness, cultural shock, or perceived discrimination. Yi et al. [23] conducted a study in a major university in Texas on the utilization of counseling services by international students. This study aimed at understanding 
why international students seek counseling services. The data collected over six years of the study indicated that many international students, when having difficulties or psychological concerns, lean on family and friends. Unfortunately, not all students have the support they need and many people were not empathetic for hosting international students. Although the university provided a counseling service, it was not widely used by international students. Many saw counseling as a replacement for family and friends, only to be used if a student did not have any friends or relatives. An implication from this study could be that international students should be provided an understanding of possible options such as counseling as professional advice to assist in adapting to their new life in the US.

Next, many challenges also occur in the academic setting. Language is considered one of the greatest academic issues hindering smooth adjustment for international students [24]. The following studies highlighted international students' challenges in their academic learning.

Probertson et al. [25] surveyed staff's experiences with international students. The findings indicated that the staff was not empathetic due to the students' language proficiency. They criticized international students for not taking responsibility for their academic advancement. Many studies have also discussed students' challenges in language and their new life in the US. Liu [26] used her own experiences as an example to discuss her struggles as an international student in Canada. Liu expressed that her lack of English proficiency became a barrier for successful participation in host community. She could not understand what her instructors and classmates were talking about in her graduate-level classes. She even had difficulty solving everyday problems, such as taking the correct buses, grocery shopping, or asking for help.

Besides the isolation from classmates, many international students also faced the challenges from professors. For example, Terui [27] examined six international students' struggles in interacting with native speakers using ethnographic methods. Findings from this study showed that international students had to pretend to understand the conversational contents exchanged with native English speakers due to their limited language proficiency. At times, a low English proficiency level would result in a negative impression from a professor because the professor perceived that the international student was not well-prepared for class. Similarly, another study also demonstrated a problem between a professor and their international students because of language proficiency. Beoku-Betters [28] observed African female scientists who were graduate students in Western universities. The finding demonstrated that professors regularly questioned international students' ability to complete course assignments, encouraged international students to take remedial classes, and readily criticized international students' accents. The result of this type of treatment on behalf of the university professor prompted international students to feel that they did not have support when needed at school, and they perceived these responses from the professor as prejudicial attitudes toward them. These studies show that international students lack support in their academic learning. Racism and stereotypes still exist for international students, and this is an important finding to consider that universities should consider when hosting international students.

Although there are benefits that international students can contribute, many international students still experience prejudice and discrimination by American students. Charles-Toussaint and Crowson [29] examined 188 American students' negative attitudes toward international students. Findings indicated that American students worry that international students pose threats to their economic, education, physical well-being, beliefs, values, and their social status from anti-immigrant prejudice. Namely, the lack of intercultural communication causes anxiety to interact with people from different groups. When people have anxiety to interact with people from different cultures, they will create a negative stereotype concerning the behavior of newcomers. For example, Hitlan et al. [30] studied the relationship between realistic and symbolic threats and prejudice against Mexican and Arab immigrants in the Southwestern US. Finding revealed that prejudice against Mexican and Arab immigrants was related to realistic and symbolic threats.

On the contrary, Severiens and Wolff [31] found that students who feel at home, who are well-connected to fellowstudents and professors and who take part in extracurricular activities are more likely to be retained in school and successfully graduate from the university. Namely, support from family and society has a positive influence on the studysuccess of students [32].

Next, international students' challenges are also sociocultural. Arriving from a different country, international students may face many difficulties in their daily life. Coming to a new country, international students are faced with the reality of needing to find places to live and finding banks to deposit and withdraw money and transportation by finding buses or buying cars to move around and applying for credits cards. Surviving in a new community is the first lesson they have to deal with, and they need to have a support system when they newly arrive. After settling in a new place, international students will also experience cultural shock.

The above literature had discussed different examples from different populations, and these studies demonstrated the international students' acculturative stress. The acculturative stress refers to a variety of negative outcomes for international students. For example, the literature has noted that the challenges experienced by international students often trigger feelings of uneasiness, insecurity, depression, anxiety, and loss $[33,34]$ or academic pressures, language difficulties, feelings of inferiority, difficulties in adjusting to new food or cultural values, lack of support, perceived discrimination, and homesickness (e.g., $[35,36]$ ).

Although challenges and coping strategies were discussed intensively in the literature, more studies are needed to examine these challenges, however, in different contexts. This study aims to provide a guideline for a Hispanic-serving institution in the southernmost part of the US. Therefore, there is an assumption that international students would face more challenges in a less diversified context. 
TABLE 2: Demographics of the participants.

\begin{tabular}{lccccccc}
\hline & Pseudonyms & Length of residence (years) & Gender & Major & Age & Country & First language \\
\hline 1 & Liu & 1.8 years & Female & Marketing & 25 & China & Chinese \\
2 & Yang & 7 months & Female & Finance & 24 & China & Chinese \\
3 & Chen & 7 months & Female & Education & 23 & Taiwan & Chinese \\
4 & Lee & 6 months & Male & Business & 27 & Taiwanese \\
5 & Hana & 3 months & Female & Education & 26 & South Korea & Korean \\
6 & Sayuri & 2 months & Female & Exchange student & 22 & Japan & Japanese \\
7 & Kimiko & 2 months & Female & Exchange student & 21 & Japan & Japanese \\
8 & Omar & 6 months & Male & Computer science & 26 & Saudi Arabia & Arabic \\
9 & Jose & 5 months & Male & Business & 26 & Mexico & Spanish \\
10 & Mai & 6 months & Female & Marketing & 28 & Vietnam & Vietnam \\
\hline
\end{tabular}

\section{Method}

5.1. Research Design. Qualitative case study approach was adopted because the purpose of this study was to understand in depth the issue of adaptation faced by international students studying in a city in a southernmost part of the US. Case study is the most appropriate qualitative research method for the present study because it "concentrates on experiential knowledge of the case and close attention to the influence of its social, political, and other contexts" [37, page 444].

5.2. Participants. Ten participants were identified as international students who were studying in undergraduate and graduate programs in the southernmost part of the US. Using convenience sampling, representativeness was limited in this study; however, in order to generate more representativeness some demographic variables were controlled. For example, participants were selected from different countries, such as, China, Taiwan, South Korea, Japan, Saudi Arabia, and Mexico.

Having a similar background helped researchers to establish the relationship with our participants. Based on the friendship with all participants, we consider ourselves as researchers from an insider perspective. This insider role allowed us to conduct research with a population from which we are also members. We share similar identity, language, and experiential base with the participants. This insider role also allowed us a more rapid and complete acceptance by our participants. The participants were typically more open with us so that allowed for a greater depth of data to be gathered. Throughout our study, we have developed a close friendship with our participants. We met our participants at festivals and dinner parties; therefore, this relationship allowed our participants to share their experiences in the US. Table 2 lists the demographics of the ten students and they were selected based on these criteria. (1) They enrolled in an undergraduate or graduate program in a university in the US. (2) The length of residence was less than two years in the US. The length of residence may also influence the adjustment difficulties, so this study focused on students who newly arrived in this country. (3) Students had experiences taking language classes.
5.3. Data Collection. Interview sessions were held at the researcher's office or participants' apartment if participants did not have transportation. Each interview lasted $70 \mathrm{~min}-$ utes. Interviews were audiotaped or videotaped. The interview questions are related to international students' experiences since they came to study in the southernmost part of the US. We adopted the semistructured interview in this study; thus, each participant replied to the same research questions, and we can explore more information based on their responses. The rationale of using this approach is to understand the respondent's point of view rather than make generalizations about behavior. The value of this type of interview allowed for opportunities to explore areas I had not previously considered [38]. Interviews were conducted mainly in English. Interviews were transcribed immediately afterwards. Researcher's reflection and notes were also prepared to compare with interview transcripts.

5.4. Data Analysis. Informed by many qualitative studies, data analysis was primarily inductive while guided by the literature. Individual interviews were transcribed and reviewed. The data were coded through a process of open coding, and emerging themes were analyzed both individually and across interviews for further analysis.

These categories in order of coded transcripts were (1) struggles and difficulties encountered by participants in different settings (academic, social, and cultural); (2) strategies adopted to resolve these difficulties; and (3) recommendations for universities. Under each category, each theme is discussed, followed by potential strategies used and recommended by the participants.

\section{Findings and Discussions}

The findings revealed that international students encountered different challenges in the US. They have to deal with the people, society, school, psychological status, and behavioral changes in order to adapt to the new environment. Findings will be categories from academic, social, and cultural aspects. Under academic struggle, there were four themes related to their difficulties in academic learning. 
6.1. Academic Barrier. Participants spent a significant proportion of the time discussing study related issues during interviews. All participants, regardless of cultural origins, claimed that their professors were nice, professional, and approachable. However, they noted difficulties in communicating with their professors due to language barriers, cultural differences, and different expectations from professors.

Theme 1 (Interaction with Professors). The interaction and communication difficulties happened in the classroom. This happened to students both from collectivism and individualism cultures. For example, a participant (Excerpt 1) stated that it is considered rude behavior if you interrupt a professor when speaking. In addition, international students also worry about the recognition of an international student. Student expressed the recognition is important for them because they would like to have more accommodation from professors and classmates (Excerpt 2).

\section{Excerpt 1}

I also tried to raise my hand to ask question. However, I did not talk until the professors saw me. I had to wait. In Korea, it is not good to interrupt a professor's speaking. If I was ignored, and the topic I can participate is passed. The professor continued to talk with other classmates even they did not raise their hands. So, I just do not express my opinions to the professor's questions. No one will wait for me. They just continue to talk (Hana, Korea).

\section{Excerpt 2}

I was curious whether the professor noticed that I am an international student or not. I want to participate, but I worried about that he cannot understand me. I guess he might be question that I did not study hard if I can express myself clearly. Sometimes, the grading and writing are also very different. How they graded the paper was very different from what I knew. For example, they wanted me to write my idea in a more direct way, rather in a sophisticated way. I tried my best to learn in the class, and sometimes, I need more time to get used to it (Sayuri, Japan).

Theme 2 (Isolation from Classmates). Isolation occurs when fitting in and making friends occurs. International students in this study have encountered different isolation in class and their social life. These students usually take a more passive role in the beginning, but they eventually discover different strategies to involve in the social events or in the classroom discussion.

\section{Excerpt 3}

I joined the Frisbee club. When they stared to pick teammates, I was always the last one to be selected. [Researcher asked]: Why do you think they do not pick you in the beginning? I don't know why! Maybe they think I am an international student, or they are not sure who I am to join their team. I am used to it. I have to ask group who need more people to join (Ray, China).

\section{Excerpt 4}

Professors used many group discussions in class. My classmates usually did not invite me to join their group discussion. (Kimiko, Japan).

\section{Excerpt 5}

My main difficulty now is "making friends" in class and in everyday life. Now, most of my friends are from Japanese student organization. I don't know how to make friends with my classmates. I am waiting for my classmates to come to talk to me (Sayuri, Japan).

Theme 3 (Language Barrier). Language is a great hindrance in participants' academic adjustment. Many participants indicated that American English was a challenge for them although they have studied English for several years in their home countries. The language difficulties are from different accents, rate of speech, and pronunciation. For many participants, they have to spend extra time improving their English.

\section{Excerpt 6}

I cannot understand many words in listening, especially, the rate of speech and pronunciation. I am taking the English class in the U.S. I also take English class in my home country; however, they are very different. I can understand the English very well in my home country. I feel like it is more simplified version to understand. Here, it's very fast. Now, I only can hear the piece of conversation. Sometimes, I might get the wrong meaning. My classmates are laughing, but I don't (Kimiko, Japan).

\section{Excerpt 7}

English conversation skill is hard when I go to bank and call to the cable company. I rarely understand all conversation when I call the set up my internet account. I need to ask them to speak slowly, and repeat again. I feel very bad (Mai, Vietnam).

\section{Excerpt 8}

My English proficiency is not very good now. Sometimes, I really cannot understand the lecture. The reading is very difficult. They are many 
words I cannot understand. When the professor assigned us in the discussion group, I was left out. My peers might not want to let me join their group. They speak so fast, and they just say it aloud. It is hard to follow sometimes (Hana, Korea).

Theme 4 (Pressure of Parents' Expectations). Many international students carried parents' expectation when they study in the US. These expectations included the learning outcome of English language proficiency, the completion of undergraduate or graduate study, financial support, and a future career. Usually, parents spent more tuition than domestic students, so international students have more pressure to meet those expectations in a short amount of time.

\section{Excerpt 9}

When I called home, my parents always ask whether I can speak English already. It means...they expected me to speak English fluent. Or, they asked: How are my course takings? I felt very stressful to tell them when I need more time. I also want to finish my study as soon as possible due to the high cost of tuition. I planned not to go back my home country before I finished all course (Chen, Taiwan).

\subsection{Social Barrier}

Theme 5 (Communication Patterns). International students face difficulties not only in the classroom but also in their social life. For example, when international students joined different social events, they stated they had to deal with different communication patterns. For example, the giftgiving interaction is vastly different in the US from their home country. In Western culture, it is acceptable to open a gift immediately to show appreciation. However, people in the Eastern culture are not used to opening gifts in front of other people. Sometimes, it causes uneasiness for the international student. Participants also stated that the communication patterns are very different, so they have to deal with some awkwardness in the social interaction.

\section{Excerpt 10}

I went to Christmas party, and my friend gave me a card and gift. I said thank you, and put it in my bag. My friends asked me to open and read out the card. I felt embarrassed, and I said later (Chen, Taiwan).

Most participants reported experiencing social isolation and loneliness. It was particularly difficult for those students who did not have relatives or acquaintances nearby. Many of the statements in this category were related to difficulties in developing friendships with the domestic students.

\section{Excerpt 11}

I feel that there is no opportunity for me to interact with my classmate except in one or two classes. I came to study by myself, and I don't have relatives in the U.S. For my classmates, we all meet few times a week, but we did not talk about many personal things. They have their own friends and family. Usually, they disappear after class (Liu, China).

6.3. Cultural Barrier. Participants were from diverse cultures, which differed from the American culture. Therefore, culture shock was experienced [39-41] by the participants due to different types of beliefs and value systems. When entering into a new culture, they needed to deal with different value systems, communication patterns, sign and symbols of social contact, and interpersonal relationship patterns. For example, international students faced the behavioral norms towards time in different cultures. Sometimes, it could easily cause misunderstanding and uneasiness. More related specific themes are discussed in the following.

Theme 6 (Reacting to the Notion of Punctuality)

\section{Excerpt 12}

I made an appointment with a tutor in the writing center; however, I still had to wait for 30 minutes. I don't think it makes sense (Yang, China).

\section{Excerpt 13}

I had to take the driving test. Although I went earlier to wait, I still have to wait for at least 2 hours in order to get my driver license. All people were waiting for outside of the office, and I was curious why they did not let people go inside of the office. In my country, people don't have to wait. They will be assigned a ticket number, and they will be served when they are called (Hana, Korea).

Theme 7 (Reacting to Prejudice against International Students). International students noted prejudice and discrimination in their academic and social lives. Thus, they were marginalized in class or in social events. Participants stated that American peers might not understand their backgrounds, and they made conclusions for them. Participants stated that they were willing to share their background to help what Americans know about them. This statement noted that international students are willing to share their voice to promote mutual understanding across different culture.

\section{Excerpt 14}

I heard some of my friends said that they (Americans) do not like international students. I am not sure why. So, it makes me feel that I might be not popular by them. Now, I don't have too much chance to know new people. Actually, I am willing to share my background. They might 
change their thinking after that (Omar, Saudi Arabia).

6.4. Adjustment Strategies. Studying abroad is not without its challenges, and there is evidence that international students experience a range of adjustment issues that can impact their study and overall experience. While universities often provide support services for international students, the personal stories of international students, identifying challenges, and strategies to overcome them can be helpful to other international students. The following themes have provided evidences that the institution has played an important role to support international students' adjustment.

Theme 8 (Utilization of School Resources as the Strategy). According to the participants in this study, school services are needed in their academic adaption to a US campus. These services include student associations, writing center, counseling center, recreation, and various student organizations. Participants mentioned that these service centers provide them a space to release stress, to find a support group, and to gain strategies to deal with different problems. For example, many international students relied on library to borrow books, study in a quiet place, and use the lab to study. Students also sought help from writing center for paper revision. One of participants even mentioned that she made an appointment with counselor at her campus due to the pressure from school and interaction with professors.

Theme 9 (Dormitory and Campus Activities). In order to overcome these challenges, participants took an active role to explore the new society and culture. For example, few participants started to look for native English speaking roommate in order to improve their English proficiency. One of participants joined different students' organization. Through the socialization, she would like to share her cultures to other students at campus, and she would like to immerse herself to interact with other English-speaking speakers. Namely, participants take active roles to engage in different campus activities in order to broaden their social networking.

Theme 10 (Language Support). Though most international students did show proficiency in written and comprehension English when they were admitted to United States colleges and universities, they faced a number of difficulties when they had to communicate orally in an academic setting. When he studied for his major, he expected to have more language support. For example, excerpt 15 implied that this participant (Chen) expected to have a conversational partner to practice speaking.

Excerpt 15

I have taken many reading and writing English classes in my home country. When I have to communicate with people, I feel nervous to speak. Sometimes, I could not understand the slang, or they speak so fast. What I can do is go to writing center to practice speaking with tutors, or have more appointments with my conversational partners. (Chen, Taiwan).

In addition, it is also helpful to hold an orientation for international students [42]. The American educational system is very different compared to many students' background, so the orientation would help international students' readiness in living and studying in the US.

\section{Excerpt 16}

"The week before semester, I have attended the orientation, so I have met with other international students coming from different cultures. We started to hang out and I can force myself to use English. At least, I can have opportunities to use the language" (Yang, China).

Theme 11 (Campus Counseling Service). Among ten participants, there is only one participant who mentioned the resource from campus counseling center. She stayed away from her parents and friends; therefore, she felt lonely sometimes. She made several appointments with the consultant to discuss her stress, Berry [12], and the consultant provided her guidance to make her adjust.

Theme 12 (Students' Organization). Increase interaction with American students in campus is important. For example, participants stated that they discovered different students' clubs or association in order to reduce the isolation from American students. Namely, creating programs to bridge international and US culture is highly recommended. Through these interactions, students will improve language and communication skills and also provide them with opportunities to understand and adjust to US culture.

\section{Excerpt 17}

When I chose student's club, I forced myself to join American's or other international students' club. I can practice my language skills, and I also can know different cultures. I still want to hang out with students from my country, but I want to have people from different backgrounds. I can use English to communicate (Mai).

This section presents the findings and provides further interpretations of them. Findings indicated that international students faced different challenges, and they utilized different strategies to adjust themselves. For a university that hosts international students, the following sections will discuss implications drawn from this study.

\section{Implications}

Based on the findings of this study, recommendations for institutions of higher education in the US on how to assist international students in becoming successful were generated. Firstly, colleges and universities should have an English program for international students to support their language 
proficiency. Language barriers could affect students' academic learning, participation in different events, and cultural understanding. Universities can host workshops where international students become familiar with the use of colloquial English, commonly used slang words, and the social and cultural mores of the US society in order to communicate effectively both in academic and in nonacademic settings.

Secondly, for US students and faculty, they should be aware of the value of embracing international students and appreciating the diversity from each other. For example, schools could host orientation programs for learning from international students. Faculty should consider the equal access and learning opportunities for all students. American students also need to develop intercultural competence to interact with international students such as providing training for staff, who will work with international students.

Thirdly, tutoring and counseling are expected because international students need guidance to succeed in their academic learning, and their psychological stress should be supported. Fourthly, universities should offer international students a special orientation about US culture and overall academic culture. Such efforts might include seminars by professionals, international students telling of their own experiences in the US, and organizations where friendship ties can be developed with local people.

\section{Conclusions}

Using qualitative research methods, this research explored international students' academic, social, and cultural adaption. To maintain the generalization, this study includes international students from different countries. The findings indicated that international students often face a series of transitional difficulties when they come to study in the US at universities and colleges. On the other hand, these challenges also motivate international students to develop strategies to solve problems. When they become autonomous learners, they develop new learning strategies to deal with difficulties. The adjustment and adaption takes time and effort, and it needs a lot of support from different aspects. The university is usually the first place where resources can be provided; thus the university needs to focus on the challenges faced by international students and provide more adequate support for them.

\section{Limitation and Future Research}

The findings of the present study should be carefully interpreted because this study focused on a particular group of international students at a specific institution. Thus, generalizability of the findings beyond this group of international students is limited. Due to the time and word limit, this study did not further report other variables, such as motivation, cultural background, personality, and attitude, toward living and studying in the US. Future studies should consider looking at other variables closely for these groups.

\section{Conflict of Interests}

The authors declare that there is no conflict of interests regarding the publication of this paper.

\section{References}

[1] P. G. Altbach and J. Knight, "The internationalization of higher education: motivations and realities," Journal of Studies in International Education, vol. 11, no. 3-4, pp. 290-305, 2007.

[2] Institute of International Education, "Top 25 places of origin of international students," Open Doors Report on International Educational Exchange 2009/10-2010/11, 2011, http://www.iie .org/opendoors.

[3] Open Doors Fast Facts, “Open door report," 2012, http://www .iie.org/Services/Project-Atlas/United-States/International-Students-In-US.

[4] Open Doors Fast Facts, Open Doors 2013: International students in the United States and study abroad by American students are at all-time high, 2013, http://www.iie.org/Who-WeAre/News-and-Events/Press-Center/Press-releases/2013/201311-11-Open-Doors-Data.

[5] D. Celleja, "The world at your door," Canadian Business, vol. 73, no. 20, pp. 108-111, 2000.

[6] M. R. Hammer, M. J. Bennett, and R. Wiseman, "The intercultural development inventory: a measure of intercultural sensitivity," International Journal of Intercultural Relations, vol. 27, pp. 421-443, 2003.

[7] W. F. Hull, Foreign Students in the United States of America: Coping Behavior within the Education Environment, Praeger, New York, NY, USA, 1978.

[8] O. Ozturgut and C. Murphy, "Literature vs. practice: challenges for international students in the U.S.", International Journal of Teaching and Learning in Higher Education, vol. 22, no. 3, pp. 374-385, 2009.

[9] M. G. Constantine, M. Kindaichi, S. Okazaki, K. A. Gainor, and A. L. Baden, "A qualitative investigation of the cultural adjustment experiences of Asian international college women," Cultural Diversity and Ethnic Minority Psychology, vol. 11, no. 2, pp. 162-175, 2005.

[10] E. Yoon and T. A. A. Portman, "Critical issues of literature on counseling international students," Journal of Multicultural Counseling and Development, vol. 32, no. 1, pp. 33-44, 2004.

[11] J. W. Berry, U. Kim, T. Minde, and D. Mok, "Comparative Studies of acculturative stress (Canada)," International Migration Review, vol. 21, no. 3, pp. 491-511, 1987.

[12] J. W. Berry, "Acculturative stress," in Handbook of Multicultural Perspective on Stress and Coping, P. T. P. Wong and L. C. J. Wong, Eds., pp. 287-298, Springer, New York, NY, USA, 2006.

[13] J. W. Berry, Understanding the Process of Acculturation for Primary Prevention, Mental Health Technical Assistance Center, University of Minnesota, Minneapolis, Minn, USA, 1988.

[14] C. Ward and A. Kennedy, "Where's the culture in cross-cultural transition? Comparative studies of sojourner adjustment," Journal of Cross-Cultural Psychology, vol. 24, no. 2, pp. 221-249, 1993.

[15] C. Ward, C.-H. Leong, and M. Low, "Personality and sojourner adjustment: An exploration of the big give and cultural fit proposition," Journal of Cross-Cultural Psychology, vol. 35, no. 2, pp. 137-151, 2004.

[16] D. Sam, P. Vedder, and C. Ward, "Psychological and sociocultural adjustment," in Immigrant Youth in Cultural Transition: 
Acculturation, Identity, and Adjustment Across National Contexts, J. W. Berry, J. Phinney, and D. Sam, Eds., pp. 117-142, Lawrence Erlbaum, Hillsdale, NJ, USA, 2006.

[17] G. Bradley, "Responding effectively to the mental health needs of international students," Higher Education, vol. 39, no. 4, pp. 417-433, 2000.

[18] E. A. Erichsen and D. U. Bolliger, "Towards understanding international graduate student isolation in traditional and online environments," Educational Technology Research and Development, vol. 59, no. 3, pp. 309-326, 2011.

[19] J. J. Lee and C. Rice, "Welcome to America? International student perceptions of discrimination," Higher Education, vol. 53, no. 3, pp. 381-409, 2007.

[20] I. G. Msengi, "Sources of stress and its impact on health behaviors and academic performance of international student sat a comprehensive Midwestern University," International Journal of Global Health \& Health Disparities, vol. 5, no. 1, pp. 55-69, 2007.

[21] X. Zheng, "Re-interpreting silence: Chinese international students' verbal participation in U.S. universities," The International Journal of Learning, vol. 17, no. 5, pp. 451-464, 2010.

[22] J. Russell, D. Rosenthal, and G. Thomson, "The international student experience: three styles of adaptation," Higher Education, vol. 60, no. 2, pp. 235-249, 2010.

[23] J. K. Yi, J. G. Lin, and Y. Kishimoto, "Utilization of counseling services by international students," Journal of Instructional Psychology, vol. 30, pp. 333-346, 2003.

[24] F. J. Galloway and J. R. Jenkins, “The adjustment problems faced by international students in the United States: a comparison of international students and administrative perceptions at two private, religiously affiliated universities," NASPA Journal, vol. 42, no. 2, pp. 175-187, 2005.

[25] M. Probertson, M. Line, S. Jones, and S. Thomas, "International students, learning environments and perceptions: a case study using the Delphi technique," Higher Education Research and Development, vol. 19, no. 1, pp. 89-102, 2000.

[26] L. Liu, "An international graduate student's ESL learning experience beyond the classroom," TESL Canada Journal, vol. 29, no. 1, pp. 77-92, 2011.

[27] S. Terui, "Second language learners'coping strategy in conversations with native speakers," Journal of International Students, vol. 2, no. 2, pp. 168-183, 2011.

[28] J. Beoku-Betters, "African women pursuing graduate studies in the sciences: racism, gender bias, and the Third World marginality," NWSA Journal, vol. 16, no. 1, pp. 116-135, 2004.

[29] G. C. Charles-Toussaint and H. M. Crowson, "Prejudice against international students: the role of threat perceptions and authoritarian dispositions in U.S. students," The Journal of Psychology: Interdisciplinary and Applied, vol. 144, no. 5, pp. 413428, 2010.

[30] R. T. Hitlan, K. Carillo, M. A. Zárate, and S. N. Aikman, "Attitudes toward immigrant groups and the effects of the 9/11 terrorist attacks," Peace and Conflict: Journal of Peace Psychology, vol. 13, no. 2, pp. 1-18, 2007.

[31] S. Severiens and R. Wolff, "A comparison of ethnic minority and majority students: social and academic integration, and quality of learning," Studies in Higher Education, vol. 33, no. 3, pp. 253266, 2008.

[32] P. Wilcox, S. Winn, and M. Fyvie-Gauld, "It was nothing to do with the university, it was just the people': the role of social support in the first-year experience of higher education," Studies in Higher Education, vol. 30, no. 6, pp. 707-722, 2005.
[33] M. G. Constantine, S. Okazaki, and S. O. Utsey, "Self-concealment, social self-efficacy, acculturative stress, and depression in African, Asian, and Latin American international college students," American Journal of Orthopsychiatry, vol. 74, no. 3, pp. 230-241, 2004.

[34] M. Wei, P. P. Heppner, M. J. Mallen, T.-Y. Ku, K. Y.-H. Liao, and T.-F. Wu, "Acculturative stress, perfectionism, years in the United States, and depression among Chinese international students," Journal of Counseling Psychology, vol. 54, no. 4, pp. 385-394, 2007.

[35] D. S. Sandhu and B. R. Asrabadi, "Development of an acculturative stress scale for international students: preliminary findings," Psychological Reports, vol. 75, no. 1, pp. 435-448, 1994.

[36] C. J. Yeh and M. Inose, "International students' reported English fluency, social support satisfaction, and social connectedness as predictors of acculturative stress," Counselling Psychology Quarterly, vol. 16, no. 1, pp. 15-28, 2003.

[37] R. E. Stake, "Qualitative case study," in Handbook of Qualitative Research, N. Denzin and Y. Lincoln, Eds., pp. 443-466, Sage, 2005.

[38] S. Reinharz, Feminist Methods in Social Research, Oxford University Press, New York, NY, USA, 1992.

[39] M. Birnbaum, B. Cardona, M. Milian, and M. Gonzalez, "Strangers in a strange land: how non-traditional international adult students see a United States University," Journal of International Education \& Leadership, vol. 2, no. 2, pp. 1-16, 2012.

[40] R. F. Chapdelaine and L. R. Alexitch, "Social skills difficulty: model of culture shock for international graduate students," Journal of College Student Development, vol. 45, no. 2, pp. 167184, 2004.

[41] Y. Kwon, "Factors affecting international students' transition to higher education institutions in the United States: from the perspective of the office of international students," College Student Journal, vol. 43, no. 4, pp. 1020-1037, 2009.

[42] D. S. Sandhu and R. R. Asrabadi, "An assessment of psychological needs of international students: implications for counseling and psychotherapy," Tech. Rep. ED 350550, ERIC Document Reproduction Service, 1991. 

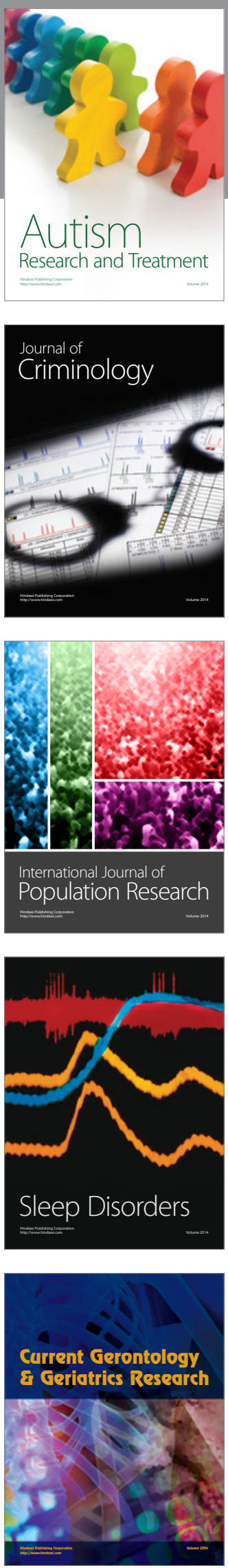
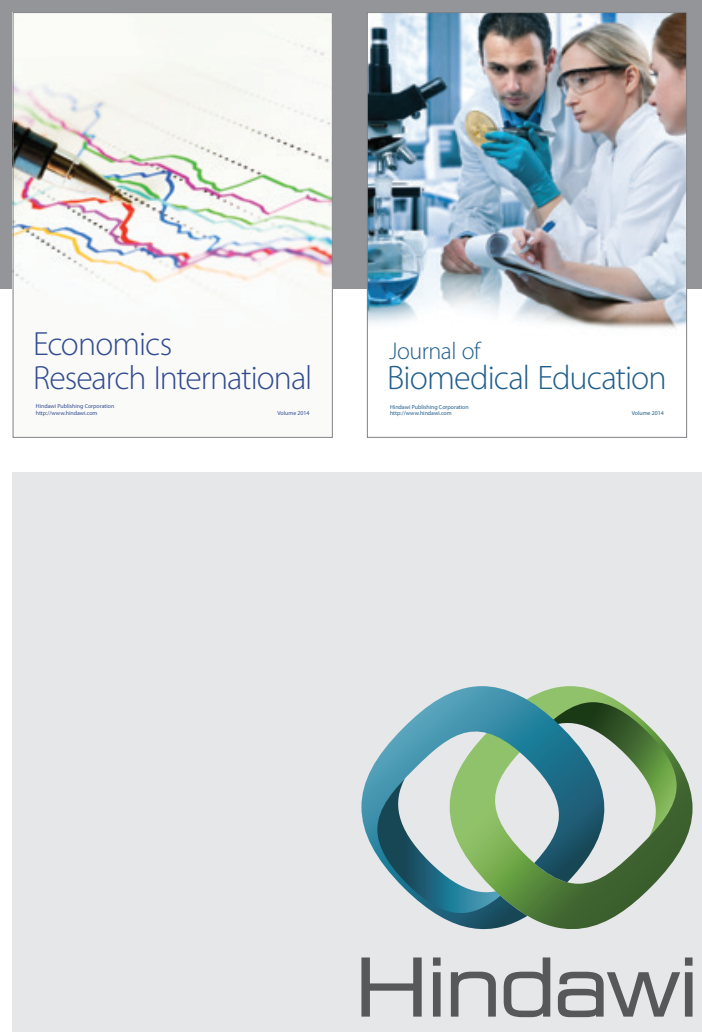

Submit your manuscripts at

http://www.hindawi.com
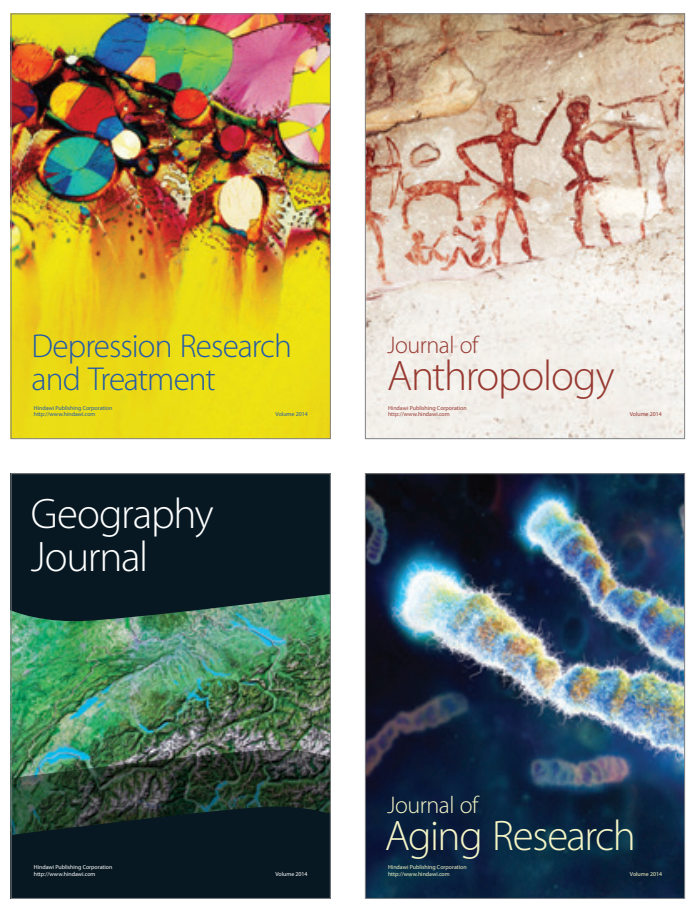
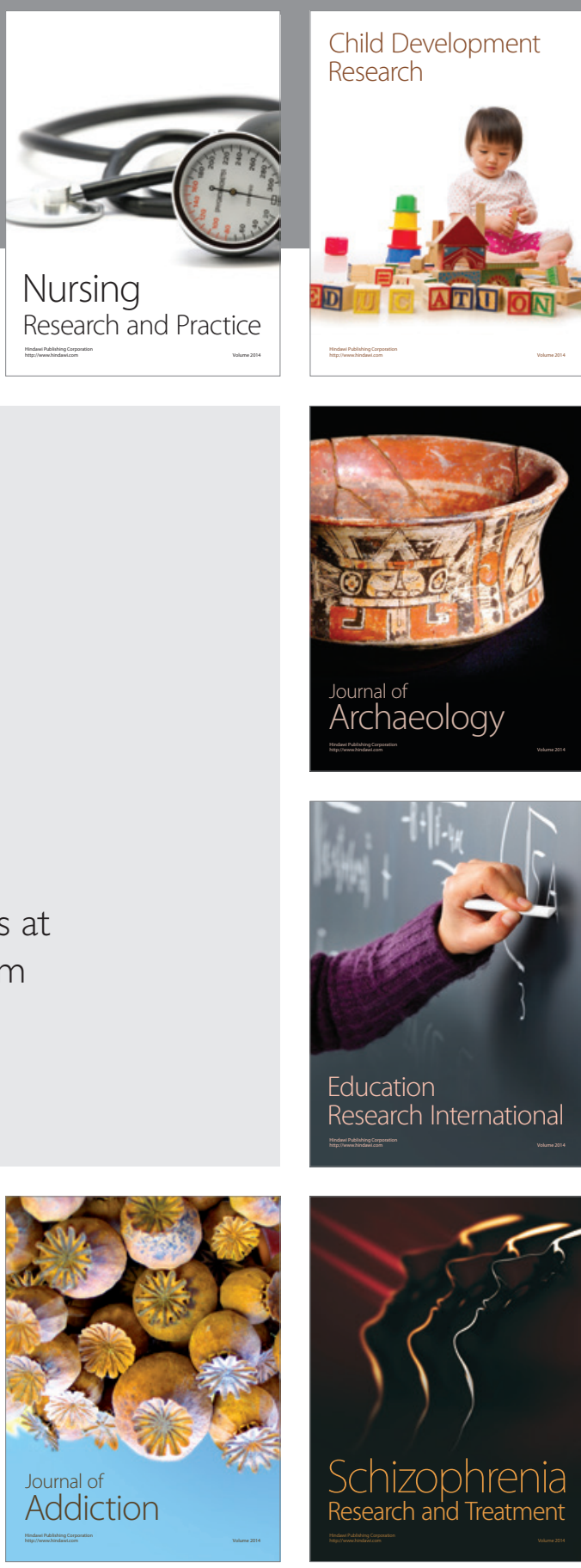

(D)
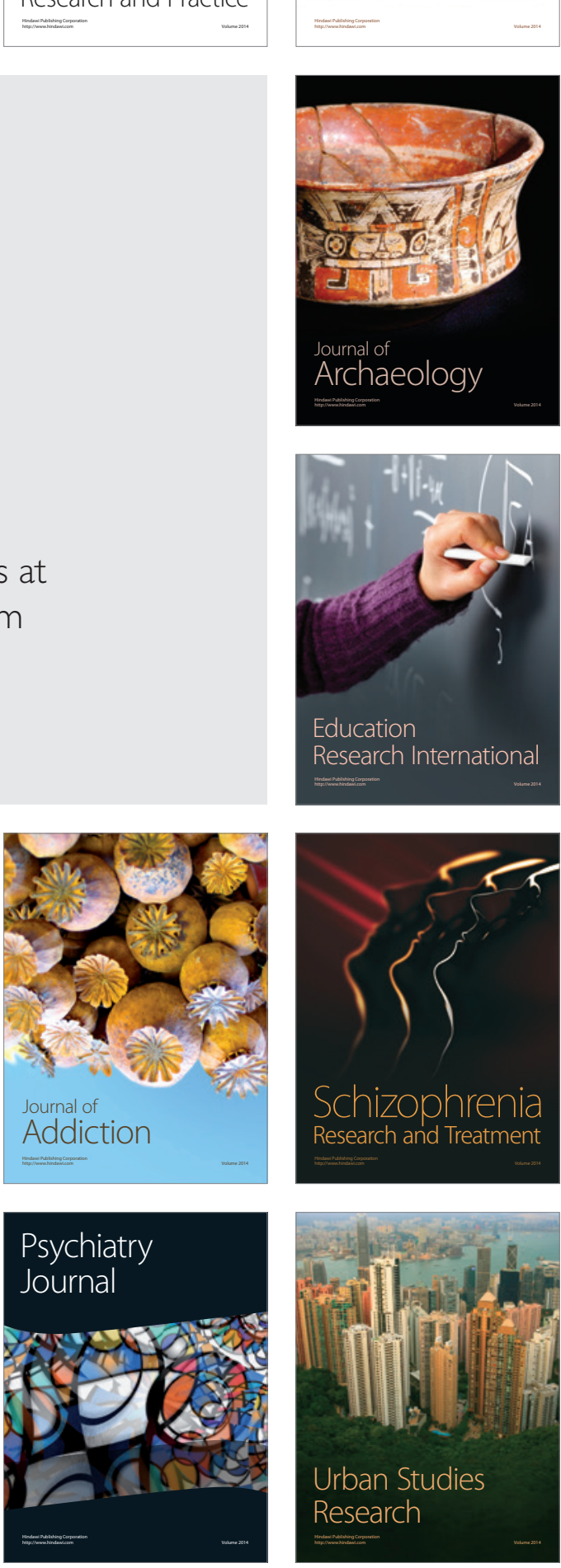